\title{
Risk Factors, Time Course and Treatment Effect for Restenosis After Successful Percutaneous Transluminal Coronary Angioplasty of Chronic Total Occlusion
}

\author{
Stephen G. Ellis, MD, Richard E. Shaw, PhD, Gary Gershony, MD, Ronald Thomas, PhD, \\ Gary S. Roubin, MB, PhD, John S. Douglas, Jr., MD, Eric J. Topol, MD, Simon H. Startzer, MD, \\ Richard K. Myler, MD, and Spencer B. King III, MD
}

Advances in technology and operator experience, and increased use of angiography early after myocardial infarction have led to greater use of percutaneous transluminal coronary angioplasty (PTCA) for chronic, total coronary artery occlusions. To better assess long-term outcome, 257 consecutive patients with successful PTCA of a total occlusion with late angiographic follow-up from 484 patients (53\%) with PTCA success were reviewed. The mean \pm standard deviation patient age was $54 \pm$ 10 years, $79 \%$ were men, the duration of total occlusion was $11 \pm 15$ weeks and the post-PTCA diameter stenosis was $24 \pm 12 \%$. Eighty-two, 27 and $63 \%$ of patients received long-term aspirin, dipyridamole and warfarin therapy, respectively. Angiography at $\mathbf{8} \pm \mathbf{8}$ months demonstrated restenosis ( $\geq \mathbf{5 0} \%$ diameter stenosis) in $\mathbf{4 1} \%$ of patients restudied within 6 months and in $66 \%$ of patients restudied within 12 months by life table analysis. In multivariate regression analysis of 19 variables, 2 were independently correlated with the occurrence of restenosis: post-PTCA diameter stenosis $>\mathbf{3 0} \%$ $(p=0.02)$ and coronary artery dilated (left anterior descending and right coronary arteries greater than the left circumflex coronary artery) $(p=0.05)$. In log rank analysis that also considered the timing of angiographic detection of restenosis, dilatation of a proximal left anterior descending stenosis was also a significant predictor of restenosis $(\mathbf{p}=\mathbf{0 . 0 1})$, and dilatation within 4 weeks of the presumed time of occlusion was only weakly predictive $(p=0.11)$. Thirty-five patients ( $27 \%$ of those with restenosis) had reocclusion at the site of PTCA, but only 3 patients (2\%) had an associated myocardial infarction. There was no relative beneficial effect of any treatment on the risk of restenosis. Thus, (1) restenosis after PTCA of chronic total occlusion is very common; (2) restenosis is predicted by the angioplasty results and angioplasty site; (3) the clinical detection of restenosis does not appear to plateau at 6 months; (4) reocclusion is not uncommon, but seldom results in myocardial infarction; and (5) there was no apparent relative treatment effect of aspirin, dipyridamole or warfarin.

(Am J Cardiol 1989;63:897-901)

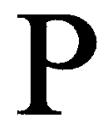
crcutaneous transluminal coronary angioplasty (PTCA) of totally occluded coronary arteries, an extension of the technique first applied to coronary arteries by Gruentzig in $1977,{ }^{1}$ is recognized to have a lower primary success rate ${ }^{2-4}$ and a higher restenosis rate 2,3 $^{2,3}$ than PTCA of subtotally occluded arteries, but may provide long-term relief from angina in some patients. Advances in angioplasty technology and operator experience, as well as increasing performance of coronary angiography early after myocardial infarction, have led to an increased opportunity to dilate subacute and chronically totally occluded coronary arteries. Such occlusions account for about $10 \%$ of all PTCAs currently undertaken. ${ }^{4}$ Knowledge of the intermediate and long-term angiographic results in such patients is derived from analyses of few patients. ${ }^{2,3}$ This study analyzes the time course and correlates-including medical therapy - of restenosis in a large cohort of patients.

\section{METHODS}

Patients: Through December 1986, elective coronary angioplasty was successfully performed (final diameter stenosis $<50 \%$ ) in 484 patients with $\geq 1$ chronically occluded coronary artery or arteries at 3 institu-

From the Department of Internal Medicine, Division of Cardiology, University of Michigan Medical Center, Ann Arbor, Michigan, the Departments of Medicine and Radiology, the Andreas Gruentzig Cardiovascular Center, Emory University School of Medicine, Atlanta, Georgia, and the San Francisco Heart Institute, Daly City, California. Manuscript received November 7, 1988; revised manuscript received and accepted January 26, 1989.

Address for reprints: Stephen G. Ellis, MD, University of Michigan Medical Center, 1500 East Medical Center Drive, UH B1 F245, Ann Arbor, Michigan 48109-0022. 
TABLE I Characteristics of Patients With and Without FollowUp Angiograms

\begin{tabular}{|c|c|c|c|}
\hline Characteristic & $\begin{array}{l}\text { Follow-Up } \\
\text { Anglogram } \\
\text { Available } \\
(n=257)\end{array}$ & $\begin{array}{l}\text { No Follow-Up } \\
\text { Angiogram } \\
\text { Avallable } \\
(n=227)\end{array}$ & $p$ Value \\
\hline Age (yrs) & $54 \pm 10$ & $56 \pm 11$ & NS \\
\hline Male gender (\%) & 79 & 78 & NS \\
\hline Hypertension (\%) & 40 & 38 & NS \\
\hline Diabetes mellitus (\%) & 8 & 9 & NS \\
\hline Hypercholesterolemı (\%) & 26 & 17 & 0.001 \\
\hline Unstable angina (\%) & 20 & 25 & NS \\
\hline \multicolumn{4}{|l|}{ Vessel site dilated (\%) } \\
\hline Proximal LAD & 19 & 17 & NS \\
\hline Mid/distal LAD & 27 & 25 & NS \\
\hline Proximal LCX & 7 & 7 & NS \\
\hline Mid/distal LCX & 15 & 12 & NS \\
\hline Proximal RCA & 14 & 13 & NS \\
\hline Mid/distal RCA & 18 & 26 & NS \\
\hline Bypass graft & 0.4 & 0.9 & NS \\
\hline $\begin{array}{l}\text { Associated regional wall } \\
\text { motion abnormality (\%) }\end{array}$ & 64 & 63 & NS \\
\hline Collaterals (\%) & 72 & 77 & NS \\
\hline $\begin{array}{l}\text { Duration of total } \\
\text { occlusion (wks) }\end{array}$ & $9 \pm 21$ & $6 \pm 9$ & NS \\
\hline Post-PTCA stenosis (\%) & $24 \pm 12$ & $24 \pm 12$ & NS \\
\hline Post-PTCA gradient $(\mathrm{mm} \mathrm{Hg})$ & $12 \pm 8$ & $10 \pm 7$ & NS \\
\hline $\begin{array}{l}\text { Uncomplicated intimal } \\
\text { dissection }(\%)\end{array}$ & 26 & 22 & NS \\
\hline Warfarin treatment (\%) & 63 & 60 & NS \\
\hline Aspirn treatment (\%) & 82 & 75 & NS \\
\hline Dipyridamole treatment $(\%)$ & 29 & 38 & NS \\
\hline
\end{tabular}

tions (Emory University Hospital, San Francisco Heart Institute and University of Michigan) for whom followup medical therapy was known. Patients were excluded if the total occlusion was known or suspected to be $\leq 72$ hours old, patients whose angioplasty was complicated by myocardial infarction (creatine kinase $>3 \times$ normal with a positive MB fraction), emergency bypass surgery or death, and patients for whom the medical treatment regimen after PTCA (aspirin, dipyridamole, coumadin) was not known. Of these patients, angiographic followup was available at $\geq 4$ months or until the time of documented restenosis in 257 (53\%), who form the study population.

Definitions: Chronic total occlusion was defined as an occlusion with TIMI 0 or 1 anterograde flow 5 that, on the basis of clinical information (date of myocardial infarction or change in pattern of angina) or, failing this, angiographic grounds (date of angiography at which time the vessel was last known to be patent), was felt to have been totally occluded for more than 3 days.

Intimal dissection was defined in accordance with the National Heart, Lung, and Blood Institute PTCA Registry definition. ${ }^{6}$

Regional wall motion in the area supplied by the totally occluded artery was described as normally contractile, moderately hypocontractile, severely hypocontractile, or akinetic or dyskinetic as modified from the Coronary Artery Surgery Study Scoring System. ${ }^{7}$

Restenosis was defined as residual diameter stenosis $\geq 50 \%$ at angiographic follow-up. ${ }^{8}$ Although other defi- nitions have been advocated, ${ }^{9-11}$ this was chosen because it is used clinically most often, because its use would allow direct comparison of results with similar large studies ${ }^{8}$ and because this information was available from each of the 3 institutions. Percent diameter stenosis was expressed as the mean of measurements made in at least 2 different angiographic projections. Measurements were made using an electronic caliper system (sites 1 and 2), previously validated against a computer system based on an edge-detection algorithm ${ }^{12}$ or by a validated computer-based edge-detection system $^{13}$ (site 3 ).

Unstable angina pectoris was defined as worsening of the severity of angina pattern within 2 months of PTCA, as distinguished from stable angina (no change in angina pattern within the last 2 months) or no angina at a restricted level of activity after myocardial infarction.

Follow-up: Repeat angiography was recommended at 6 months after PTCA or with the return of symptoms at sites 1 and 2, but was performed only as clinically indicated at site 3 . Angiograms performed at other institutions were referred to the site that had performed PTCA for angiographic analysis. When $>1$ follow-up angiogram was available, that which allowed for the longest follow-up without intervention was evaluated.

Statistical analysis: The clinical variables analyzed as possible risk factors for restenosis were age, gender, duration of total occlusion (to the nearest week), history of hypertension, history of diabetes mellitus, history of elevated cholesterol and unstable angina pectoris as an indication for PTCA. The angiographic variables included vessel site undergoing PTCA (proximal left anterior descending, mid or distal left anterior descending, proximal left circumflex, mid or distal left circumflex, proximal right coronary artery, mid or distal right coronary artery, and bypass graft), collaterals beyond the site dilated and regional wall motion in the area supplied by the vessel dilated. The procedural variables were post-PTCA percent diameter stenosis, post-PTCA translesional gradient and presence of post-PTCA intimal dissection. The 2 post-PTCA variables comprised treatment medications (aspirin, dipyridamole, coumadin) and the time from PTCA to angiographic restudy.

A chi-square test was used to assess differences in the incidence of categorical variables between groups. A Student $t$ test or 1-way analysis of variance was used to assess differences in the distribution of continuous variables between groups. A 2-sided $p$ value of $\leq 0.05$ was considered indicative of a significant difference, but values of $0.05<p \leq 0.15$ are included in the text for completeness. ${ }^{14}$ Multivariate least square regression analysis and $\log$ rank analyses were used to assess the effect of variables on restenosis. Because of the intersite variation in indications for angiographic restudy and significant difference in restudy rates between hospitals, stratification for the variable "hospital site" was always performed before entering other variables. When the effects of post-PTCA medical therapy were assessed, "hospital site" and the angiographic and clinical variables found to be independent correlates of restenosis by 
multivariate analysis were stratified before entering the post-PTCA medical treatment information. Multivariable results presented are from the multivariate regression analysis, unless otherwise stated.

In addition, the timing and likelihood of documented restenosis after PTCA of total and subtotal occlusions (pre-PTCA diameter stenosis $\leq 95 \%$ ) were compared directly by log rank analysis in patients having angioplasty of both types of stenoses on the same date. For patients with $>1$ subtotal stenosis dilated, 1 site was randomly chosen to be used in this analysis.

\section{RESULTS}

Patient characteristics and follow-up: The characteristics of the 257 patients in the study population are compared with those of the 227 patients without angiographic follow-up in Table I. The groups differed ( $p$ $\leq 0.05$ ) only in regard to incidence of hypercholesterolemia. The rate of angiographic follow-up was $59 \%$ at site $1,48 \%$ at site 2 and $24 \%$ at site $3(\mathrm{p}<0.001)$.
Restenosis: The true incidence of restenosis cannot be determined without $100 \%$ angiographic follow-up. ${ }^{15}$ However, among the patients with angiographic followup, $41 \%$ had restenosis documented within 6 months, $66 \%$ had restenosis documented within 12 months and 77\% had restenosis documented within 24 months (Figure 1A). Thirty-seven patients $(29 \%)$ with restenosis had a 50 to $69 \%$ stenosis at follow-up, 41 patients (32\%) had a 70 to $89 \%$ stenosis and 51 patients $(39 \%)$ had a 90 to $100 \%$ stenosis, including 35 patients $(27 \%)$ with total occlusion at the sitc dilated. However, only 3 patients with restenosis had a late clinical event consistent with a myocardial infarction.

Clinical and angiographic risk factors for restenosis: In multivariate testing, a diameter stenosis $>30 \%$ after angioplasty (coefficient $=0.16, p=0.022$ ) and dilatation of a left circumflex coronary stenosis (coefficient $=-0.18, \mathrm{p}=0.025$ ) independently predicted risk of restenosis (constant $=0.52$ ). In log rank analyses, dilatation of a proximal left anterior descending stenosis
FIGURE 1. Freedom from angiographic documentation of restenosis. $A$, occurrence and timing of documentation of restenosis in all patients with angiographic follow-up. B, comparison of occurrence and timing of documented restenosis of chronic total and subtotal stenoses in 56 patients having angioplasty of a subtotal occlusion on the same date as the index angioplasty for chronic total occlusion.

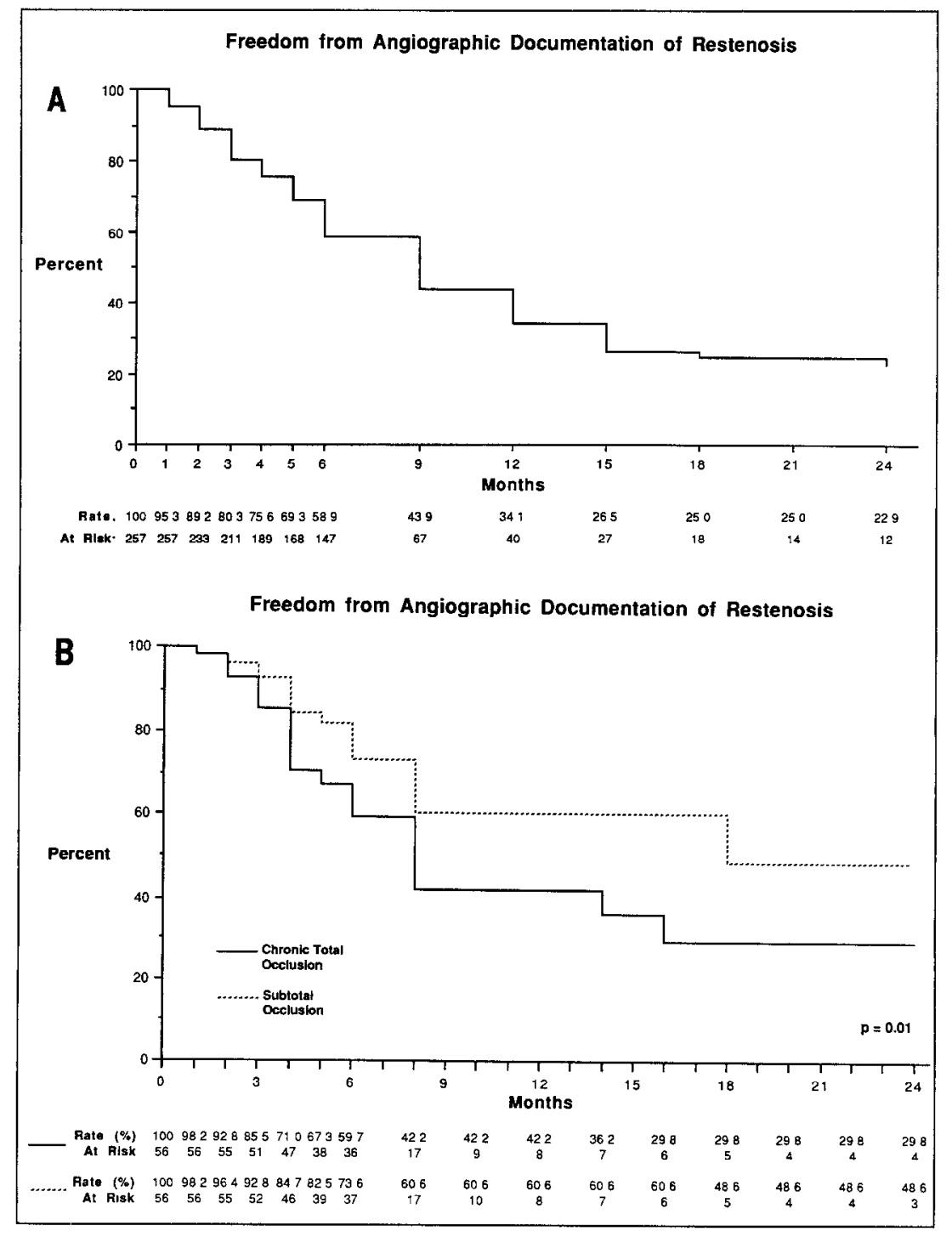

THE AMERICAN JOURNAL OF CARDIOLOGY APRIL 15, 1989 
was also a significant predictor of restenosis $(p=0.01)$, whereas dilatation within 4 weeks of the presumed time of occlusion was weakly predictive of restenosis $(p=$ 0.11 ). Of note, of the 26 patients with myocardial infarction within 10 days of PTCA, $40 \%$ had restenosis documented within 3 months, 50\% had restenosis within 6 months and $71 \%$ had restenosis within 12 months by life table analysis. No other variables predicted risk of restenosis.

Restenosis after percutaneous transluminal coronary angioplasty of chronic total versus subtotal occlusions: Fifty-six patients had PTCA of both total and subtotal occlusions. Their age was $55 \pm 10$ years and $82 \%$ were men. The distribution of sites dilated differed $(\mathrm{p}=0.04)$, potentially biasing the subtotal group toward an increased risk of restenosis due to the preponderance of left anterior descending stenoses. ${ }^{8}$ However, results after PTCA were similar (difference not significant) for the 2 groups: $39 \%$ left anterior descending, $25 \%$ left circumflex and $36 \%$ right coronary arteries in the chronic total occlusion group, with a final percent diameter stenosis of $25 \pm 12 \%$, and $59 \%$ left anterior descending, 9\% left circumflex and $32 \%$ right coronary arteries in the subtotal occlusion group, with a final percent diameter stenosis of $22 \pm 11 \%$. As shown in Figure $1 \mathrm{~B}$, documented restenosis nonetheless occurred more commonly at the sites of prior chronic total occlusion ( $p$ $=0.01$ )

Treatment effect: After stratifying for hospital site, post-PTCA diameter stenosis and site dilated, therapy had no significant effect on the risk of restenosis (warfarin coefficient $=0.10, p=0.18$; aspirin coefficient $=$ $-0.05, \mathrm{p}=0.58$; dipyridamole coefficient $=0.05, \mathrm{p}=$ 0.50 ).

Repeat percutaneous transluminal coronary angioplasty: Angiographic follow-up after repeat PTCA for restenosis after PTCA for chronic total occlusion is limited. Of 20 patients with successful PTCA of a subtotally occlusive restenosis, 15 (75\%) had a documented restenosis within 6 months. Of 8 patients with successful PTCA of a repeat total occlusion, all had restenosis within 6 months.

\section{DISCUSSION}

Reports from relatively small series of patients with elective PTCA of total coronary occlusion suggest that primary success is less than, and the restenosis rate is higher than, PTCA for subtotal occlusion, but that it can provide long-term relief from angina in some patients. $2,3,16$

In this study of 484 patients with successful PTCA of chronic total occlusion, 257 (53\%) had angiographic follow-up. Of these patients, 41,66 and $75 \%$ had documentation of restenosis within 6,12 and 18 months by actuarial methods. As with many other restenosis studies, a true restenosis rate cannot be determined because of a lack of complete angiographic follow-up. Nonetheless, these results can be compared with results from studies with similar follow-up rates. For instance, Leim- gruber et al, ${ }^{8}$ with an angiographic follow-up rate of $57 \%$ in patients with PTCA of subtotal stenoses, found restenosis in $30 \%$ of patients, which would suggest that PTCA of chronic total occlusions does have a much higher incidence of restenosis than PTCA of subtotal occlusions. In that serics, the 33 paticnts with angiographic follow-up of a dilated chronic total occlusion who had a restenosis rate of $48 \%$ were excluded from analysis. Kereiakes et $\mathrm{al}^{3}{ }^{3}$ who found restenosis in $75 \%$ of 12 patients restudied from 40 patients with successful chronic angioplasty of a total occlusion, Serruys et al, ${ }^{2}$ who found restenosis in $40 \%$ of 20 patients restudied from 28 patients and Clark et al, ${ }^{17}$ who found restenosis in $56 \%$ of 45 patients from 97 patients, have reported similarly high restenosis rates in this setting.

This study confirms the higher risk of restenosis after PTCA of chronic total occlusions and, contrary to most reports reviewing patients with subtotal occlusion and PTCA, shows that restenosis after PTCA for chronic total occlusion commonly is discovered more than 6 months after the index PTCA. Late $100 \%$ occlusion was seen in $27 \%$ of patients with restenosis in this series but, fortunately, associated infarction was rare $(2 \%)$. Both of these features of restenosis after dilation of chronic total occlusion may be due to the ischemiasparing effect of ready collateral formation in such patients (present in $72 \%$ of them before PTCA in this series). Thus, the exact timing of the occurrence of restenosis in these patients is problematic.

The risk factors for restenosis after PTCA for chronic total occlusion appear to be similar to those for PTCA for subtotal occlusions. ${ }^{8,11}$ The relatively small number of patients in this series limited the statistical power for detecting risk factors for restenosis.

Finally, although this was not a randomized study, there was no apparent differential effect on restenosis with the use of aspirin, dipyridamole or warfarin. This has also been shown to be the case after PTCA of subtotal occlusions, ${ }^{18,19}$ but the expected high incidence of thrombus associated with chronic total occlusions and the probable relation of thrombus to late restenosis ${ }^{20,21}$ led to hope that use of these agents might decrease the risk of restenosis in this setting. Other mechanisms of plaque removal or displacement, or pharmacologic inhibition of neointimal regrowth in this setting, are needed.

Limitations: This study is limited by the relatively low rate of angiographic restudy typical of clinical practice, by differences in the criteria for and rates of restudy at the 3 angioplasty centers, by the relatively small number of patients studied and by the nonrandomized allocation of medical treatment after PTCA. For these reasons, a deliberate attempt was made to avoid assessment of a true restenosis rate. In addition, comparisons with trials with greatly different rates of angiographic restudy were avoided. Nevertheless, this is the largest angiographic study of long-term results after PTCA for chronic total occlusion, and the lack of even an apparent trend toward a beneficial treatment effect would suggest a modest true effect, if any. 
Acknowledgment: The authors wish to express their gratitude for the expert secretarial assistance provided for the preparation of this manuscript by Judy Hanson.

\section{REFERENCES}

1. Gruentzig A. Transluminal dilatation of coronary artery stenosis (letter) Lancet 1978,1:263.

2. Serruys PW, Umans V, Heyndricks GR, van den Brand M, De Feyter PJ, Wijns W, Jaski B, Hugenhoitz PG Elective PTCA of totally occluded coronary arteries not associated with acute myocardial infarction; short-term and long-term results. Eur Heart J 1985;6:2-12.

3. Kereiakes DJ, Selmon MR, McAuley BJ, McAuley DB, Sheehan DJ, Simpson JB. Angioplasty in total coronary occlusion: experience in 76 consecutive patients. JACC 1985,6 526-533.

4. Detre K, Holubkov R, and the Co-Investigators of the National Heart, Lung, and Blood Institutes Percutaneous Transluminal Coronary Artery Registry. Percutaneous transluminal coronary angioplasty in 1985-1986 and 1977-1981. $N$ EngI J Med 1988,318:265-270.

5. TIMI Study Group. The thrombolysis and myocardial infarction (TIMI) trial: phase I findings. N Engl J Med 1985;312:932-936.

6. Cowley MJ, Dorros G, Kelsey SF, van Raden M, Detre KM. Acute coronary events associated with percutaneous transluminal coronary angioplasty. $A m J$ Cardiol 1984;53:12C-16C.

7. Principal Investigators of CASS and Their Associates. National Heart, Lung, and Bloud Institute Coronary Artery Surgery Study. Circulation 1981,79:1-40. 8. Leimgruber PP, Roubin GS, Hollman J, Cotsonis GA, Meier B, Douglas JS, King SB, Gruentzig AR. Restenosis after successful coronary angioplasty in patients with single-vessel disease. Circulation 1986,73.710-717.

9. Kaltenback M, Kobert G, Scherer D, Vallbrach TC. Recurrence rate after successful coronary angioplasty. Eur Heart J 1985;6:6276-6281.

10. Serruys PW, Luijten HE, Beatt KJ, Geuskens R, De Feyter PJ, van den Brand M, Reiber JH, Ten Katen HJ, Van Es GA. Hugenholtz PG. Incidence of restenosis after successful coronary angioplasty' a time-related phenomenon. A quantitated angiographic study in 342 consecutıve patients at $1,2.3$, and 4 months. Circulation 1988,77.361-371.

11. Myler RK, Topol EJ. Shaw RE, Stertzer SH, Clark DA, Fishman-Rosen J, Murphy C. Multıple vessel coronary angioplasty: classification, results in patterns of restenosis in 494 consecutive patients. Cathet Cardiovasc Diagn 1987;13.1-15. 12. Scoblionko DP, Brown BG, Mitten S, Caldwell JH, Kennedy JW, Bolson EL, Dodge HT. A new digital electronic caliper for measurement of coronary arterial stenosis: comparison with visual estrmates in computer-assisted measurements. Am J Cardiol 1984,53:689-693.

13. Mancinı GBJ, Simon SB, McGillem MJ, LeFree MT, Friedman HZ, Vogel RA. Automated quantitatıve coronary arteriography: morphologic and physiologic validation in vivo of a rapid digital anglographic method. Circulation 1987, 75:452-460.

14. Pocock SJ, Hughes MD, Lee RJ. Statistıcal problems in reporting clinical trials. $N$ Engl J Med 1987;317:426-432.

15. Myler RK, Shaw RE, Stertzer SH, Clark DA, Fishman J, Murphy MC. Recurrence after coronary angioplasty Cathet Cardiovasc Diagn 1987;13:77-86. 16. Wexman MP, Clark DA, Murphy MC, Fishman Rosen J, Shaw RE, Stertzer SH, Myler RK. Patient selection, complications and predictors of success in PTCA of total occlusions (abstr) Circulation 1985:72:III-141.

17. Clark DA, Wexman MP, Murphy MC, Fishman-Rosen J, Shaw RE Stertzer SH, Myler RK. Factors predicting recurrence in patients who have had angioplasty (PTCA) of totally occluded vessels (abstr). JACC 1986;7:20A.

18. White CW, Knudson M, Schmidt D, Chisholm RJ, Vandormael M, Morton B, Roy L. Khaja F, Reitman M, and the Ticlopidine Study Group. Neither Ticlopidine or aspirin-dipyridamole prevents restenosis post PTCA: results from a randomized placebo controlled multi-center trial (abstr) Circulation 1987.76:IV-213

19. Schwartz L, Bourassa M, Lesperance J, Aldridge H, David PR, Henderson M, Hudon G, Kazim F. Failure of anti-platelet agents to reduce restenosis after PTCA and double blind placebo controlled trial (abstr). JACC 1988,11:236A. 20. Moore A, Friedman R, Singal D, Gauldi EJ, Blajchman M. Inhibition of 1njury induced by thromboatherosclerotic lesions by anti-platelet serum in rabbits. Thromb Diath Haemorrh 1976;35:70-81.

21. Faxon D, Sanborn $T$, Haudenschild $C$, Ryan $T$. The effect of antiplatelet therapy on restenosis after experimental angioplasty. Am J Cardiol 1984,53:72C $76 C$. 